\title{
Erikoiskasvien juuriston ja ravinteiden allokoinnin monimuotoisuus
}

\author{
Kaija Hakala ja Marjo Keskitalo \\ MTT Kasvintuotannon tutkimus, Kasvinviljely ja biotekniikka, 31600 Jokioinen. e-mail: \\ kaija.hakala@mtt.fi,marjo.keskitalo@mtt.fi
}

Jokioisilla järjestetyssä astiakokeessa tutkittiin yhdeksän erikoiskasvin (hamppu, kinua, kitupellava, kumina, morsinko, nokkonen, ruokohelpi, tattari ja öljypellava) ja kahden yleisemmän viljelykasvin (ohra ja timotei) biomassan ja ravinteiden (typpi, kalsium, kalium, magnesium ja fosfori) allokaatiota kasvin eri osiin. Astiat olivat suuria 11 litran vetoisia astioita, ja maaperä hienoa hietaa. Astiat lannoitettiin ennen koetta NPK- ja hivenravinneliuoksilla siten, että ravinteita oli ylimäärin kaikkien kasvien tarpeisiin. Lannoitus oli sama kaikille kasveille.

Monivuotiset kasvit kumina, morsinko, nokkonen, ruokohelpi ja timotei allokoivat jo ensimmäisenä kasvuvuonna enemmän biomassaa juuristoon kuin yksivuotiset hamppu, kinua, kitupellava, tattari, öljypellava ja ohra. Suurin juuri-versosuhde oli kuminalla (2), toiseksi suurin morsingolla (1.5). Suurimat kokonaisbiomassat olivat kuminalla ja ruokohelpillä.

Monivuotisilla kasveilla, joilla juurimassaa oli enemmän, oli myös enemmän ravinteita varastoituna juuriin. Varsinkin kuminalla ja morsingolla tämä oli selvästi nähtävissä, kun puolet kasvien Mg-, P- ja N -määristä oli juuristossa. Kumina keräsi kasvustoonsa yleisestikin ottaen paljon ravinteita, koska sen biomassa oli suuri. Tämä logiikka ei kuitenkaan toteutunut ruokohelven kohdalla, jonka biomassa oli kasveista toiseksi suurin, mutta joka keräsi sanottavasti vain fosforia ja typpeä nyt tutkituista ravinteista. Sen sijaan biomassaltaan keskinkertainen kinua oli paras magnesiumin, fosforin ja kaliumin kerääjä. Hamppu ja nokkonen keräsivät erityisen paljon kalsiumia kokonaisbiomassaansa, tattari oli huomattava fosforin kerääjä. Typpeä kasvit keräsivät tasaisemmin; sen määrä astiaa kohden riippui lähinnä biomassan määrästä.

Koska juuret jäävät korjuun jälkeen maahan, ne ovat tärkeitä ravinteiden lyhytaikaisia varastoja. Jos maasta kuitenkin halutaan poistaa ravinteita esim. valuma-alueiden suojakaistojen avulla, tärkeä rooli on korjuussa poistuvilla ravinteilla. Typpeä ja fosforia pellolta olisi näiden nyt tutkittujen kasvien mukana poistunut eniten siemensatoa tuottavilla kasveilla eli yksivuotisilla ohralla, tattarilla ja kitupellavalla. Öljyhamppu ja öljypellava poistaisivat erityisen paljon typpeä ja fosforia maasta, koska niistä korjataan sekä siemenet että varret. Muita ravinteita poistuisi eniten kasveilla, joista korjataan biomassaa (edellä mainitut hamppu ja öljypellava sekä morsinko, nokkonen ja ruokohelpi). Yksivuotisilla siemenkasveilla muut ravinteet kuin suurin osa typestä ja osa fosforista palautuvat suurimmaksi osaksi maahan, jos puintijäte silputaan ja palautetaan peltoon. Kaksivuotisen kuminan siemensadon sisältämiä ravinteita ei vielä tässä vaiheessa ole voitu määrittää, koska toisen kasvuvuoden (jolloin siemenet valmistuvat) tuloksia ei vielä ole saatavissa.

Tutkimus osoittaa, että erikoiskasvien välillä on eroja ravinteiden allokoinnissa eri kasvinosiin. Nyt tutkimusta jatketaan kenttäkokeen avulla. Sen tavoitteena on saada tietoa erityisesti maanpäällisen biomassan muodostumisesta ja ravinteiden allokoitumisesta tilanteessa, jossa kasveja lannoitetaan kasvikohtaisesti ja kasvien kasvua rajoittavat todelliset ympäristöolot. Monivuotisten kasvien kohdalla biomassan määrän muuttuminen vuosien edetessä on myös oleellista ottaa huomioon tehtäessä johtopäätöksiä niiden ravinteiden käytöstä. Kokeen tulosten perusteella pyritään päättelemään, missä määrin viljelykasvin valinnalla voidaan vaikuttaa pellon ravinnetasapainoon, orgaanisen aineen pitoisuuteen ja siten pellon kasvukuntoon. Tiettyjä kasveja voitaisiin myös käyttää köyhdyttämään peltomaata ravinteista esim. valuma-alueiden suojakaistoilla.

Asiasanat: ravinteet, monimuotoisuus, biodiversiteetti, juuristo 


\section{Johdanto}

Yksipuolinen kasvinviljely, etenkin jos viljellään kevätkylvöisiä, yksivuotisia viljakasveja, saattaa aiheuttaa maan ravinnetasojen epätasapainoa, maan rakenteen huononemista ja humuspitoisuuden vähenemistä. Uusien viljelykasvien ottaminen viljelykiertoon parantaa tutkimusten mukaan sekä maan kasvukuntoa että pellon oheiseliöiden rikkautta (kts. Marjo Keskitalo \& al. 2006, Maataloustieteen päivät -seminaarikirjoitus). Tässä tutkimuksessa on arvioitu sitä, miten erilaiset viljelykasvit vaikuttavat maan kasvukuntoon ensinnäkin tuomalla systeemiin orgaanista ainesta juurten muodossa ja toiseksi sitomalla ravinteita väliaikaisiin varastoihin tai köyhdyttämällä maata korjuussa poistuvien ravinteiden kautta. Koska tutkimuksessa erityishuomio oli juurten kasvussa ja ravinteiden allokoinnissa niihin, koe tehtiin astiakokeena, jossa kasvin tuottaman juurimassan selvittäminen ja juurten erottelu maasta oli yksinkertaisempaa kuin kenttäkokeen avulla tehtynä.

\section{Aineisto ja menetelmät}

Tutkittavana oli kuusi yksivuotista kasvilajia: Ohra, tattari, kitupellava (Camelina), kinua, öljypellava ja hamppu ja viisi monivuotista lajia: timotei, kumina (kaksivuotinen), ruokohelpi, morsinko (kaksivuotinen) ja nokkonen. Kasvit kylvettiin vuoden 2003 keväällä valkoisiin muovisiin altakasteluruukkuihin, jotka oli täytetty n. 11 litralla Jokioisten pellolta tuotua hietamaata ja lannoitettu seuraavasti (astiaa kohti): $1.5 \mathrm{~g} \mathrm{~N}, 0,6 \mathrm{~g} \mathrm{P}, 1,5 \mathrm{~g} \mathrm{~K}, 1,61 \mathrm{~g} \mathrm{Ca}, 0,45 \mathrm{~g} \mathrm{Mg}, 0,06 \mathrm{~g} \mathrm{Na}, 0,015 \mathrm{~g} \mathrm{Fe}, \mathrm{Zn}$ ja $\mathrm{Mn}, 0,0075 \mathrm{~g} \mathrm{Cu}$, ja 0,0015 g B ja Mo. Kasvusto korjattiin niiden tuleennuttua (yksivuotiset) tai myöhään kasvukauden lopulla (monivuotiset). Kasvusto eroteltiin korjattavaan osaan, muuhun maanpäälliseen biomassaan ja juuriin. Näistä ryhmistä määritettiin kuivapaino, typpipitoisuus ja pääravinteet $\mathrm{Ca}, \mathrm{K}, \mathrm{P}$ ja $\mathrm{Mg}$.

\section{Tulokset ja tulosten tarkastelu}

Kumina ja ruokohelpi tuottivat kasvun ensimmäisenä vuonna eniten biomassaa. Suuri osa tästä biomassasta oli juuristoa (Kuva 1). Yleensäkin monivuotiset kasvit tuottivat juurimassaa enemmän kuin yksivuotiset (Kuva 1). Monivuotiset kasvit tuottivat eniten juurimassaa myös suhteessa maanpäälliseen biomassaan (Kuva 2).

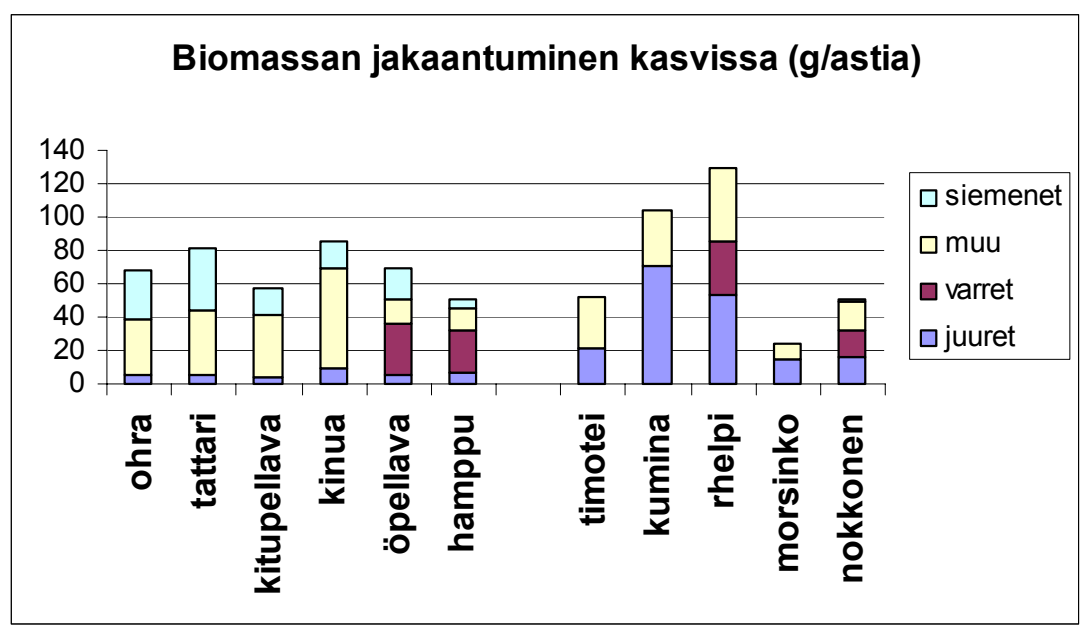

Kuva 1. Biomassan jakaantuminen siemeniin, muuhun biomassaan, varsiin ja juuriin astiakokeen 11 kasvissa. Tulos g kuiva-ainetta/astia. 


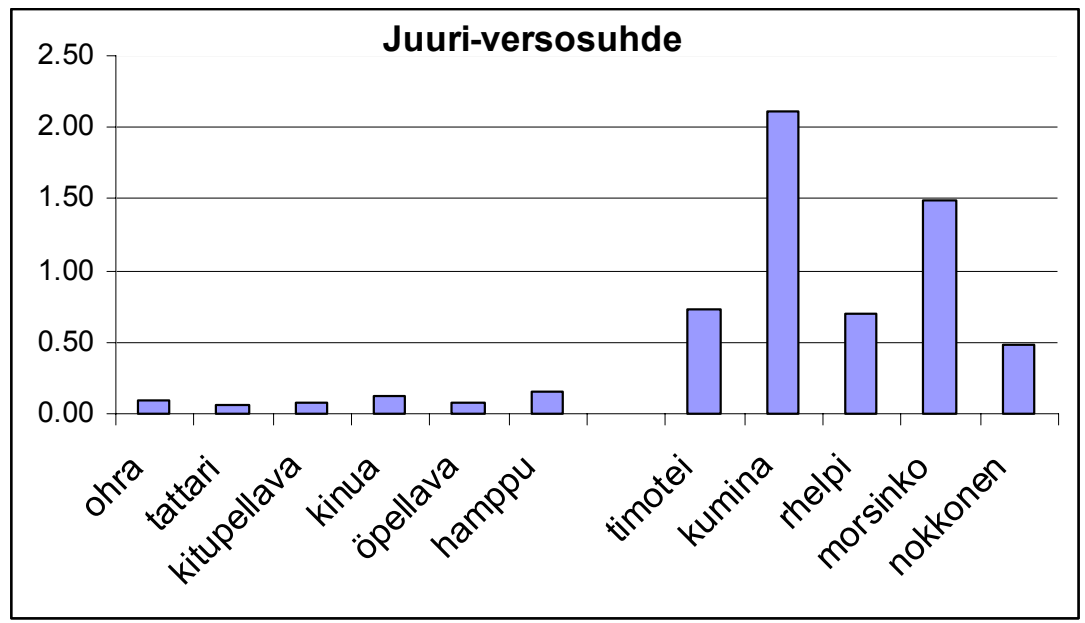

Kuva 2. Juuri/versosuhde (=juurten kuivapaino/muun biomassan kuivapaino) astiakokeen kasveilla.

Juurten ja muiden kasvinosien sisältämät $\mathrm{Ca}, \mathrm{K}, \mathrm{Mg}, \mathrm{P}$ ja $\mathrm{N}$-pitoisuudet vaihtelivat kasvista toiseen. Kun ottaa huomioon kasvin ja sen osien biomassan painon, nämä ravinteet jakaantuivat kasvin korjattavaan ja muuhun osaan sekä juuriin kuvan 3 mukaisesti.

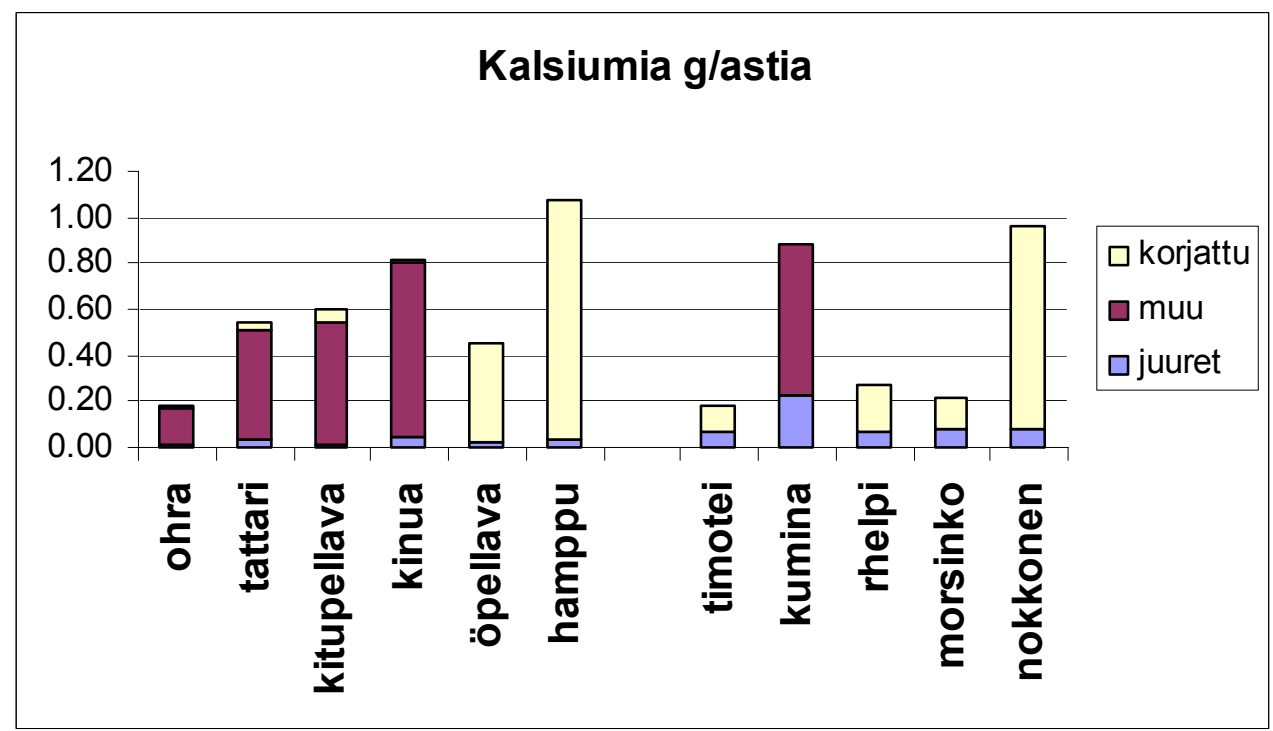

$\mathbf{A}$

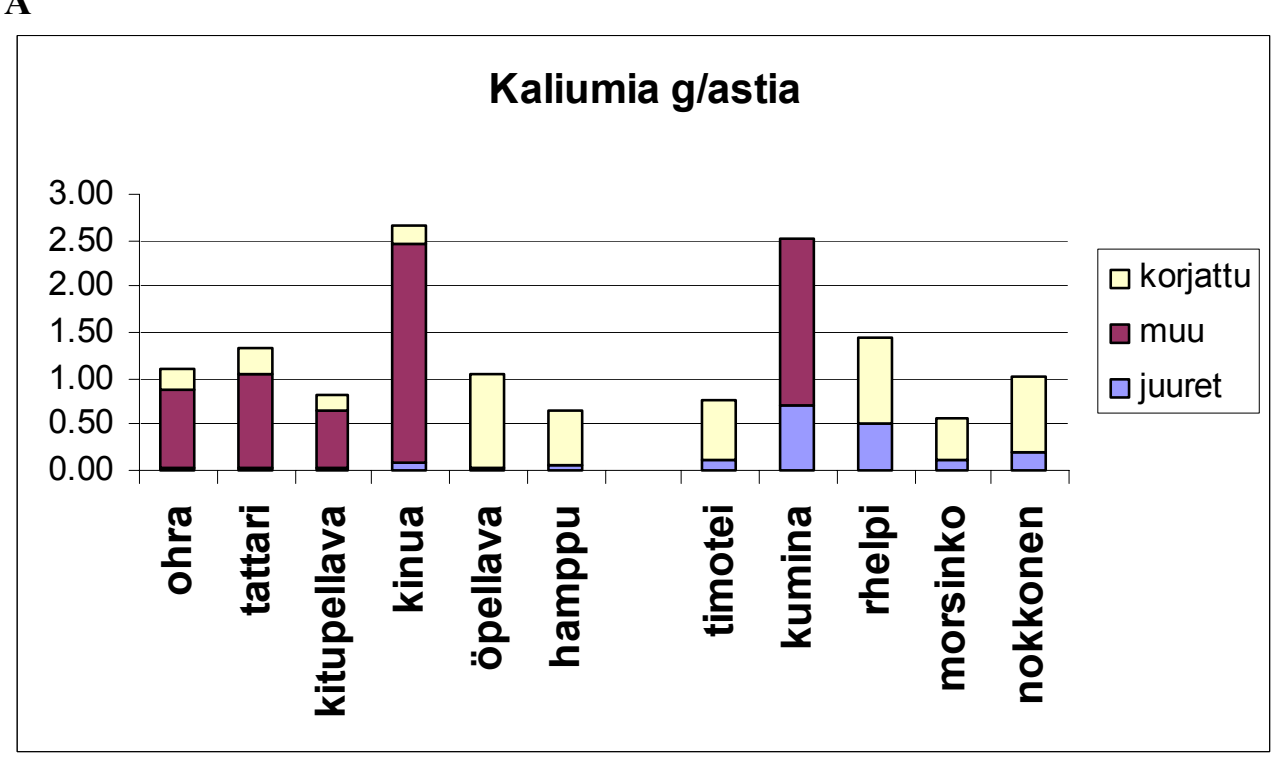

B 


\section{Magnesiumia g/astia}

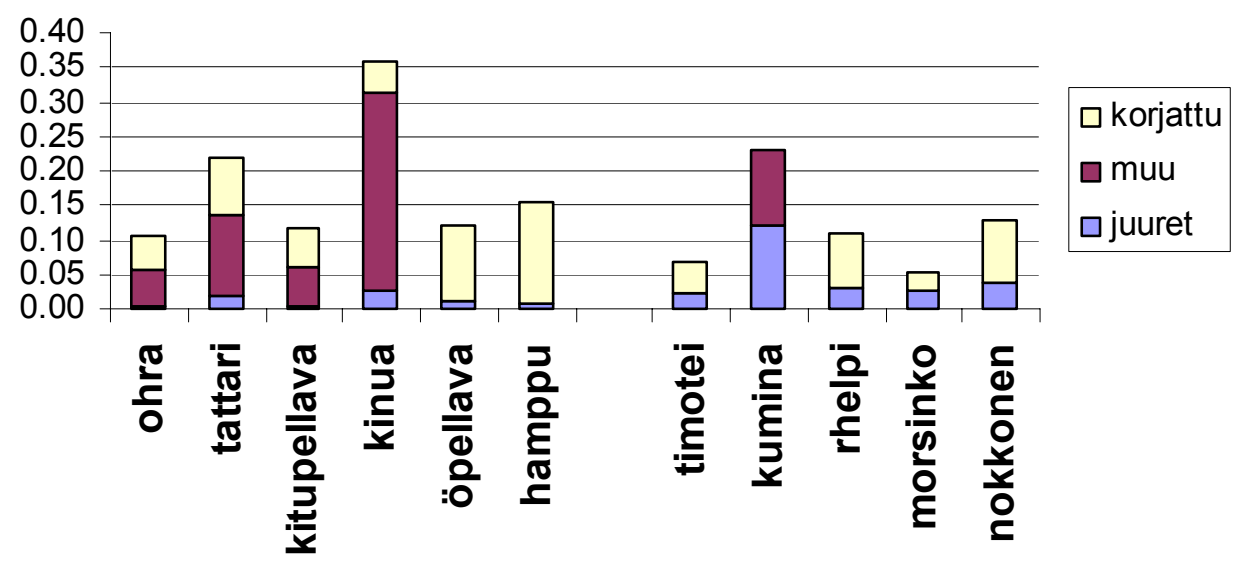

C

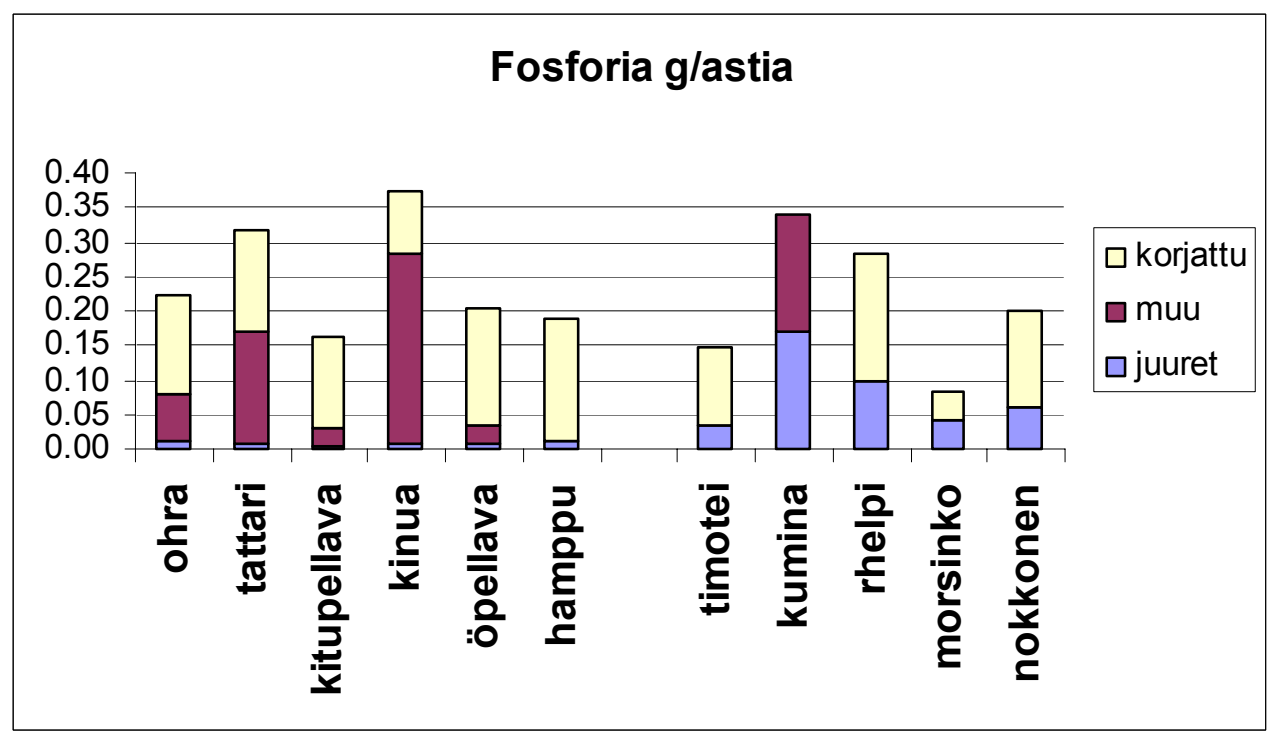

D

\section{Typpeä g/astia}

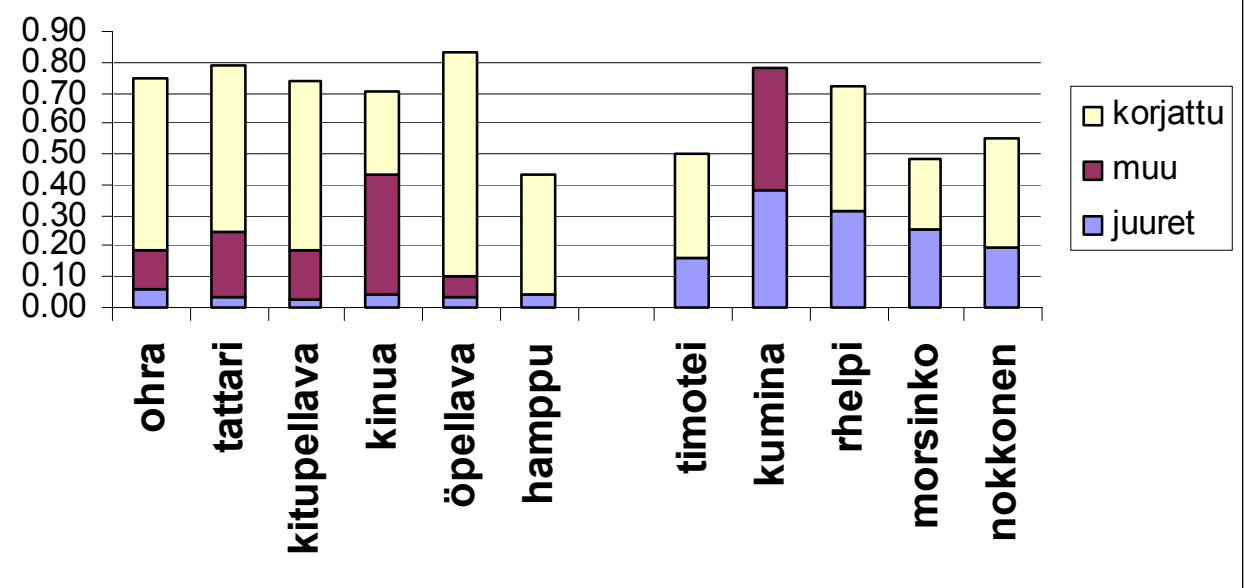

$\mathbf{E}$

Kuva 3. Ravinnemäärät eri kasveissa ja kasvinosissa, g/astia. A) Ca, B) $\mathrm{K}, \mathrm{C}$ ) $\mathrm{Mg}$, D) P ja E) N 
Monivuotisilla kasveilla, joilla juurimassaa oli enemmän, oli myös enemmän ravinteita varastoituna juuriin. Varsinkin kuminalla ja morsingolla tämä oli selvästi nähtävissä, kun puolet kasvien $\mathrm{Mg}$-, P- ja $\mathrm{N}$-määristä oli juuristossa. Kumina keräsi kasvustoonsa yleisesti ottaen paljon ravinteita, koska sen biomassakin oli suuri. Tämä logiikka ei kuitenkaan toteutunut ruokohelven kohdalla, jonka biomassa oli kasveista toiseksi suurin, mutta joka keräsi sanottavasti vain fosforia ja typpeä nyt tutkituista ravinteista. Sen sijaan biomassaltaan keskinkertainen kinua oli paras magnesiumin, fosforin ja kaliumin kerääjä. Hamppu ja nokkonen keräsivät erityisen paljon kalsiumia kokonaisbiomassaansa, tattari oli huomattava fosforin kerääjä. Typpeä kasvit keräsivät tasaisemmin; sen määrä astiaa kohden riippui lähinnä biomassan määrästä.

Paitsi juuristo, pellolle jää myös korjaamaton kasvinosa, joka silputaan pellon pintaan. Astiakokeen tulokset antavat viitteitä siitä, miten paljon ravinteita kustakin kasvista jää peltoon ja miten paljon korjataan pois (Kuva 3). Yksivuotisilla siemensatokasveilla korjatussa ja siis pellolta pois viedyssä kasvinosassa oli suhteellisen paljon fosforia ja typpeä. Korjatut $\mathrm{Ca}, \mathrm{K}$ ja $\mathrm{Mg}$-määrät sen sijaan olivat pieniä. Kasveista, joista korjattiin sekä siemenet että varret (hamppu ja öljypellava), tuli samalla korjattua suurin osa kasvin ravinteista, varsinkin kun ne yksivuotisina eivät tuottaneet paljon juuristomassaa. Näin hampun mukana poistui runsaasti kalsiumia ja öljypellavan mukana typpeä. Monivuotisista biomassakasveista ruokohelven ja nokkosen mukana korjattiin runsaasti fosforia ja typpeä. Lisäksi nokkosen mukana tuli korjatuksi paljon kalsiumia. Monivuotisten kasvien tulokset jäivät astiakokeessa puutteellisiksi, koska koe tehtiin vain yhtenä vuotena. Monivuotisten kasvien vaikutuksia voidaan arvioida siten vain ensimmäisen vuoden perusteella. On todennäköistä, että biomassan tuotto ja juurten kasvu muuttuvat monivuotisilla kasveilla vuosien mittaan. Myös ravinteiden käytössä ja allokoinnissa kasviin voi ajan mittaan syntyä eroja astiakokeeseen verrattuna.

Huomioonotettavana tekijänä on myös se, että kaikkia astioita lannoitettiin samalla tavalla ja runsaammin kuin pelto-oloissa tehdään. Käytetty siemenmäärä astiaa kohti oli myös jonkin verran suurempi kuin pelto-oloissa käytetään. Se on saattanut vaikuttaa juurten ja biomassan muodostumiseen sekä eri kasvinosien kehittymiseen eri tavalla kuin pellolla. Monivuotisten kasvien kohdalla astiakasvatuksen vaikutus on todennäköisesti suurin. Jonkin verran on varmaan myös eroja kasvien ottamissa ravinteiden määrissä ja allokoinnissa, kun niitä viljellään eri kasvuoloissa.

\section{Johtopäätökset}

Tutkimus osoittaa, että erikoiskasvien välillä on eroja ravinteiden allokoinnissa eri kasvinosiin. Nyt tutkimusta jatketaan kenttäkokeen avulla. Sen tavoitteena on saada tietoa erityisesti maanpäällisen biomassan muodostumisesta ja ravinteiden allokoitumisesta tilanteessa, jossa kasveja lannoitetaan kasvikohtaisesti ja kasvien kasvua rajoittavat todelliset ympäristöolot. Monivuotisten kasvien kohdalla biomassan määrän muuttuminen vuosien edetessä on myös oleellista ottaa huomioon tehtäessä johtopäätöksiä niiden ravinteiden käytöstä. Kokeen tulosten perusteella pyritään päättelemään, missä määrin viljelykasvin valinnalla voidaan vaikuttaa pellon ravinnetasapainoon, orgaanisen aineen pitoisuuteen ja siten pellon kasvukuntoon. Tiettyjä kasveja voitaisiin myös käyttää köyhdyttämään peltomaata ravinteista esim. valuma-alueiden suojakaistoilla.

\section{Kirjallisuus}

Keskitalo, M., Eriksson, C., Hakala, K., Ikonen, A., Kaipainen, S., Kurppa, S., Palojärvi, A., Soini, K., Turunen, H., Vuorio, H. 2006. Kohti monimuotoista viljelyä erikoiskasvien avulla. Maataloustieteen päivät 2006, Viikki, Helsinki. www.smts.fi 